\title{
Accurate Structure Prediction for Protein Loops Based on Molecular Dynamics Simulations with RSFF2C
}

\author{
Jia-Jie Feng, ${ }^{1}$ Jia-Nan Chen, ${ }^{1}$ Wei Kang, ${ }^{* 3}$ and Yun-Dong $\mathrm{Wu}^{* 1,2,3}$
}

1. Lab of Computational Chemistry and Drug Design, State Key Laboratory of Chemical

Oncogenomics, Peking University Shenzhen Graduate School, Shenzhen 518055, China

2. College of Chemistry and Molecular Engineering, Peking University, Beijing 100871, China

3. Shenzhen Bay Laboratory, Shenzhen 518132, China

*To whom correspondence and requests for materials should be addressed.

Supplementary information

\section{Contents:}

1. Protein sequences

2. Supplementary Tables 1-5

3. Supplementary Figures 1-15

4. Rosetta-NGK and MODELLER prediction details

5. DaReUS-Loop and Sphinx prediction details 


\section{Protein sequences}

2eaq

QFSDMRISINQTPGKSLDFGFTIKWDIPGIFVASVEAGSPAEFSQLQVDDEIIAINNTKFSYNDSKEWEE AMAKAQETGHLVMDVRRYG

$5 \mathrm{w} 0 \mathrm{~g}$

LGSARRLYVGNIPFGITEEAMMDFFNAQMRLGGLTQAPGNPVLAVQINQKNFAFLEFRSVDETTQAM AFDGIIFQGQSLKIRRP

2ns0

MTVSDRELEECIRALLDARADSASICPSDVARAVAPDDWRPLMEPVREAAGRLADAGEVEVTQKGAV VDPRSARGPIRIRWTRTD

$4 \mathrm{dpb}$

IDVLLGADDGSLAFVPSEFSISPGEKIVFKNNAGFPHNIVFDEDSIPSGVDASKISMSEEDLLNAKGETF

EVALSNKGEYSFYCSPHQGAGMVGKVTVN

5 nod

VTSVAMPSYIGSSLEFTKNNLIQIVGIKEANIEVVEVTTAPAGSVEGMVVEQSPRAGEKVDLNKTRVKI SIYKPK

6elm

SMAEDTGVRVELAEEDHGRKSTIALRLWVEDPKKLKGKPKDNGAIEFTFDLEKETPDEVAQEMIESG

FFHESDVKIVAKSIRDRVALIQWRRERIWPA

$3 \mathrm{bv} 8$

ALTAEEIIQYISDAKKFTPIKVYLNGNFEGITYPESFKVFGSEQSKVIFCEADDWKPFYEAYGSQFEDIEI EMDRRNSAIPLKDL

$5 \mathrm{e} 9 \mathrm{p}$

SGEYTEIALPFSYDGAGEYYWKTDQFSTDPNDWSRYVNSWNLDLLEINGTDYTNVWVAQHQIPAAS DGYWYIHYKSGVSWGHVEIK

$4 \mathrm{bpf}$

MDFKQEVLDVLAEVCQDDIVKENPDIEIFEEGLLDAFGTVELLLAIENRFDILVPITEFDRDVWNTPN NIVNQLSELKRSHHHHHH

$6 \mathrm{fmb}$

AAAYWDCDGTEIPERNVRAAVVLAFNYRKESFHGYPAVRQFPVEDSDANWQGGAVKYYILTNKRGS YLEVFSSVGSGNKCTFVEG

$5 \mathrm{k} 21$

MGCTYTIQPGDTFWAIAQRRGTTVDVIQSLNPGVNPARLQVGQVINVPC 
$3 \mathrm{k} 3 \mathrm{v}$

ESSWRYIDTQGQIHGPFTTQMMSQWYIGGYFASTLQISRLGSTPETLGINDIFITLGELMTKLEKYDTD PFTTFDKLHV

$3 \mathrm{fdr}$

LQLDKLVNEMTQHYENSVPEDLTVHVGDIVAAPLPTNGSWYRARVLGTLENGNLDLYFVDFGDNGD CPLKDLRALRSDFLSLPFQAIEC

4qy7

GDETKMQSLVGYVVLKDNERAILITDTKAPGKEDYNLSEGQLMNKFKNNIVIVGLSEIDNTDDLKRG EKIKVWFHTRKESNPPSATIQKYELL

$3 \mathrm{dkm}$

GRENLYFQGLKYMVPGARVTRGLDWKWRDQDGSPQGEGTVTGELHNGWIDVTWDAGGSNSYRM GAEGKFDLKLAPGYDP 


\section{Supplementary Tables 1-5}

Table S1. The lengths, positions, sequences and simulation settings of the 15 loops used in our test set

\begin{tabular}{|c|c|c|c|c|c|c|c|}
\hline PDB ID & length & Res start & Resend & Sequence & $\mathrm{N}_{\text {replica }}$ & $\mathrm{T}(\mathrm{K})^{a}$ & $\operatorname{RMSD}_{\text {initial }}(\AA)^{b}$ \\
\hline 2eaq & 10 & 1047 & 1056 & QTPGKSLDFG & 32 & $293-463$ & 10.1 \\
\hline $5 \mathrm{w} 0 \mathrm{~g}$ & 10 & 176 & 185 & GGLTQAPGNP & 32 & 293-461 & 11.4 \\
\hline $2 \mathrm{~ns} 0$ & 10 & 68 & 77 & VDPRSARGPI & 32 & $289-457$ & 10.7 \\
\hline $4 \mathrm{dpb}$ & 10 & 42 & 51 & DEDSIPSGVD & 32 & $277-450$ & 12.9 \\
\hline 5 nod & 10 & 616 & 625 & TTAPAGSVEG & 40 & $293-503$ & 9.1 \\
\hline $6 \mathrm{elm}$ & 10 & 486 & 495 & LKGKPKDNGA & 40 & $293-481$ & 5.7 \\
\hline $3 b v 8$ & 11 & 30 & 40 & NFEGITYPESF & 32 & $298-537$ & 8.3 \\
\hline $5 e 9 p$ & 12 & 479 & 490 & DQFSTDPNDWSR & 32 & $293-457$ & 11.7 \\
\hline $4 \mathrm{bpf}$ & 13 & 23 & 35 & NPDIEIFEEGLLD & 40 & $298-465$ & 11.4 \\
\hline $6 \mathrm{fmb}$ & 13 & 56 & 68 & EDSDANWQGGAVK & 40 & $293-472$ & 14.0 \\
\hline $5 \mathrm{k} 2 \mathrm{l}$ & 13 & 31 & 43 & NPGVNPARLQVGQ & 32 & $293-467$ & 16.9 \\
\hline $3 \mathrm{k} 3 \mathrm{v}$ & 14 & 54 & 67 & LGSTPETLGINDIF & 32 & $293-467$ & 16.8 \\
\hline $3 \mathrm{fdr}$ & 14 & 19 & 32 & ENSVPEDLTVHVGD & 40 & $298-485$ & 11.9 \\
\hline $4 q y 7$ & 14 & 82 & 95 & LSEIDNTDDLKRGE & 40 & $277-453$ & 6.4 \\
\hline $3 \mathrm{dkm}$ & 16 & 1285 & 1300 & GLDWKWRDQDGSPQGE & 40 & $298-504$ & 16.4 \\
\hline
\end{tabular}

${ }^{a}$ Temperature range of replicas. Overall exchange acceptance ratios were around $20 \%$. ${ }^{b}$ The $\mathrm{C} \alpha$ RMSD of initial models of REMD simulations compared to crystal structures. 
Table S2. Performance of the first 3 cluster centroids of REMD Simulations with Different Force Fields

\begin{tabular}{|c|c|c|c|c|c|c|c|c|c|}
\hline $\mathrm{pdb}$ & & RSFF $2 \mathrm{C}+\mathrm{TIP} 3 \mathrm{P}$ & $\mathrm{C} 36 \mathrm{~m}+\mathrm{mTIP} 3 \mathrm{P}$ & $\mathrm{ff} 19 \mathrm{SB}+\mathrm{OPC}$ & $\mathrm{pdb}$ & & RSFF2C+TIP3P & $\mathrm{C} 36 \mathrm{~m}+\mathrm{mTIP} 3 \mathrm{P}$ & $\mathrm{ff} 19 \mathrm{SB}+\mathrm{OPC}$ \\
\hline \multirow{3}{*}{ 2eaq } & $\mathrm{Cl}^{a}$ & $2.2(69 \%)$ & $1.9(52 \%)$ & $5.4(54 \%)$ & & $\mathrm{Cl}$ & $0.9(86 \%)$ & $1.7(100 \%)$ & $3.5(20 \%)$ \\
\hline & $\mathrm{C} 2^{b}$ & $3.1(14 \%)$ & $3.7(19 \%)$ & $2.5(40 \%)$ & $5 \mathrm{w} 0 \mathrm{~g}$ & $\mathrm{C} 2$ & $2.4(7 \%)$ & & $2.4(18 \%)$ \\
\hline & $\mathrm{C} 3^{c}$ & $5.0(7 \%)$ & $4.9(19 \%)$ & $2.0(3 \%)$ & & $\mathrm{C} 3$ & $2.4(5 \%)$ & & $1.9(12 \%)$ \\
\hline \multirow{3}{*}{$2 \mathrm{~ns} 0$} & $\mathrm{Cl}$ & $0.8(100 \%)$ & $1.6(95 \%)$ & $1.0(85 \%)$ & & $\mathrm{Cl}$ & $0.7(94 \%)$ & $1.2(98 \%)$ & $0.5(100 \%)$ \\
\hline & $\mathrm{C} 2$ & & $3.4(4 \%)$ & $3.0(7 \%)$ & $4 \mathrm{dpb}$ & $\mathrm{C} 2$ & $2.5(6 \%)$ & $2.5(1 \%)$ & \\
\hline & $\mathrm{C} 3$ & & & $2.8(3 \%)$ & & $\mathrm{C} 3$ & & $3.3(1 \%)$ & \\
\hline \multirow{3}{*}{ 5nod } & $\mathrm{C} 1$ & $0.9(97 \%)$ & $1.2(18 \%)$ & $2.4(65 \%)$ & & $\mathrm{C} 1$ & $1.3(78 \%)$ & $2.8(21 \%)$ & $1.6(28 \%)$ \\
\hline & $\mathrm{C} 2$ & $3.0(3 \%)$ & $2.6(16 \%)$ & $1.7(18 \%)$ & 6elm & $\mathrm{C} 2$ & $3.1(7 \%)$ & $3.5(18 \%)$ & $1.8(20 \%)$ \\
\hline & $\mathrm{C} 3$ & & $3.7(12 \%)$ & $4.0(5 \%)$ & & $\mathrm{C} 3$ & $2.7(5 \%)$ & $2.7(17 \%)$ & $2.9(14 \%)$ \\
\hline \multirow{3}{*}{ 3bv8 } & $\mathrm{Cl}$ & $0.4(100 \%)$ & $0.9(100 \%)$ & $0.5(100 \%)$ & & $\mathrm{C} 1$ & $0.6(27 \%)$ & $5.6(52 \%)$ & $5.1(19 \%)$ \\
\hline & $\mathrm{C} 2$ & & & & $5 \mathrm{e} 9 \mathrm{p}$ & $\mathrm{C} 2$ & $2.6(16 \%)$ & $6.9(8 \%)$ & $9.9(16 \%)$ \\
\hline & $\mathrm{C} 3$ & & & & & $\mathrm{C} 3$ & $3.1(15 \%)$ & $6.5(6 \%)$ & $2.6(8 \%)$ \\
\hline \multirow{3}{*}{$4 \mathrm{bpf}$} & $\mathrm{C} 1$ & $0.4(63 \%)$ & $0.7(73 \%)$ & $0.4(78 \%)$ & & $\mathrm{Cl}$ & $1.0(97 \%)$ & $1.6(99 \%)$ & $1.9(58 \%)$ \\
\hline & $\mathrm{C} 2$ & $3.1(17 \%)$ & $3.5(22 \%)$ & $4.0(16 \%)$ & $6 \mathrm{fmb}$ & $\mathrm{C} 2$ & $2.6(1 \%)$ & & $7.2(28 \%)$ \\
\hline & $\mathrm{C} 3$ & $3.5(12 \%)$ & $3.2(2 \%)$ & $3.1(3 \%)$ & & $\mathrm{C} 3$ & $2.8(1 \%)$ & & $10.5(4 \%)$ \\
\hline \multirow{3}{*}{$5 \mathrm{k} 21$} & $\mathrm{Cl}$ & $0.5(97 \%)$ & $1.1(74 \%)$ & $0.6(94 \%)$ & & $\mathrm{Cl}$ & $2.1(15 \%)$ & $4.5(18 \%)$ & $7.2(28 \%)$ \\
\hline & $\mathrm{C} 2$ & $1.8(2 \%)$ & $2.1(4 \%)$ & $1.2(2 \%)$ & $3 \mathrm{k} 3 \mathrm{v}$ & $\mathrm{C} 2$ & $3.4(9 \%)$ & $2.9(15 \%)$ & $7.4(11 \%)$ \\
\hline & $\mathrm{C} 3$ & & $4.8(4 \%)$ & $4.8(2 \%)$ & & $\mathrm{C} 3$ & $7.0(8 \%)$ & $6.5(7 \%)$ & $7(7 \%)$ \\
\hline \multirow{3}{*}{$3 \mathrm{fdr}$} & $\mathrm{Cl}$ & $0.7(85 \%)$ & $1.0(97 \%)$ & $5.9(13 \%)$ & & $\mathrm{Cl}$ & $0.9(54 \%)$ & $2.4(80 \%)$ & $2.6(68 \%)$ \\
\hline & $\mathrm{C} 2$ & $2.4(8 \%)$ & $2.9(1 \%)$ & $9.4(10 \%)$ & 4qy7 & $\mathrm{C} 2$ & $2.7(38 \%)$ & $0.8(8 \%)$ & $1.0(31 \%)$ \\
\hline & $\mathrm{C} 3$ & $3.4(3 \%)$ & & $7.7(8 \%)$ & & $\mathrm{C} 3$ & $3.2(6 \%)$ & $2.5(5 \%)$ & \\
\hline \multirow{3}{*}{$3 \mathrm{dkm}$} & $\mathrm{Cl}$ & $4.1(56 \%)$ & $4.6(38 \%)$ & $8.1(54 \%)$ & & & & & \\
\hline & $\mathrm{C} 2$ & $7.1(7 \%)$ & $6.6(18 \%)$ & $7.7(18 \%)$ & & & & & \\
\hline & $\mathrm{C} 3$ & $8.0(5 \%)$ & $8.9(9 \%)$ & $11.1(14 \%)$ & & & & & \\
\hline
\end{tabular}

${ }^{a}$ The first cluster from REMD simulations ${ }^{b}$ The second cluster from REMD simulations ${ }^{c}$ The third cluster from REMD simulations. RMSD for each cluster is given in $\AA$ and fraction (in parenthesis) is given in percentage. 
Table S3. The number of hydrogen bonds (HBs) formed by loop residues in the top structures with Different Force Fields

The number of HBs formed within each loop region

$\begin{array}{lccccccccccccccccc} & \text { 2eaq } & 5 \mathrm{w} 0 \mathrm{~g} & 2 \mathrm{~ns} 0 & 4 \mathrm{dpb} & 5 \mathrm{nod} & 6 \mathrm{elm} & 3 \mathrm{bv} 8 & 5 \mathrm{e} 9 \mathrm{p} & 4 \mathrm{bpf} & 6 \mathrm{fmb} & 5 \mathrm{k} 21 & 3 \mathrm{k} 3 \mathrm{v} & 3 \mathrm{fdr} & 4 \mathrm{qy} 7 & 3 \mathrm{dkm} & \text { Average } \\ \text { Exp. } & 3 & 0 & 5 & 3 & 1 & 2 & 2 & 6 & 5 & 2 & 5 & 7 & 3 & 6 & 8 & \mathbf{3 . 9} \\ \text { RSFF2C+TIP3P } & 2 & 1 & 8 & 6 & 3 & 0 & 2 & 11 & 6 & 2 & 5 & 7 & 4 & 6 & 6 & \mathbf{4 . 6} \\ \text { C36m+mTIP3P } & 2 & 2 & 7 & 3 & 1 & 0 & 1 & 2 & 7 & 4 & 6 & 3 & 2 & 2 & 5 & \mathbf{3 . 1} \\ \text { ff19SB+OPC } & 6 & 3 & 5 & 3 & 6 & 1 & 2 & 4 & 7 & 3 & 5 & 5 & 3 & 6 & 12 & \mathbf{4 . 7}\end{array}$

The number of HBs formed between each loop region and the other part of the protein

2eaq 5w0g 2ns0 4dpb 5nod 6elm 3bv8 5e9p 4bpf 6fmb 5k2l 3k3v 3fdr 4qy7 3dkm Average

$\begin{array}{lllllllllllllllll}\text { Exp. } & 5 & 9 & 6 & 4 & 3 & 3 & 4 & 8 & 8 & 4 & 8 & 6 & 7 & 5 & 10 & \mathbf{6 . 0} \\ \text { RSFF2C+TIP3P } & 7 & 8 & 9 & 6 & 2 & 6 & 5 & 8 & 10 & 3 & 6 & 12 & 6 & 6 & 9 & \mathbf{6 . 9} \\ \text { C36m+mTIP3P } & 5 & 10 & 5 & 2 & 1 & 1 & 2 & 6 & 7 & 4 & 6 & 10 & 11 & 7 & 3 & \mathbf{5 . 3} \\ \text { ff19SB+OPC } & 5 & 7 & 7 & 7 & 2 & 4 & 5 & 9 & 6 & 4 & 6 & 5 & 8 & 6 & 7 & \mathbf{5 . 9}\end{array}$


Table S4. The performance of high-temperature MD simulations compared to REMD simulations with $\mathrm{C36m}+\mathrm{mTIP3P}$ force field

\begin{tabular}{|c|c|c|c|c|c|c|c|c|c|c|c|c|c|c|c|c|c|}
\hline \multicolumn{2}{|c|}{$\mathrm{C} 36 \mathrm{~m}+\mathrm{mTIP} 3 \mathrm{P}$} & \multicolumn{4}{|c|}{ REMD } & \multicolumn{4}{|c|}{$620 \mathrm{~K}$} & \multicolumn{4}{|c|}{$500 \mathrm{~K}$} & \multicolumn{4}{|c|}{$380 \mathrm{~K}$} \\
\hline $\mathrm{pdb}$ & length & clus1 & top & top10 & best & clus1 & top & top10 & best & clus1 & top & top10 & best & clus1 & top & top10 & best \\
\hline 2eaq & 10 & $52 \%$ & 1.9 & 1.9 & 1.0 & $9 \%$ & 2.4 & 2.4 & 1.0 & $22 \%$ & 2.2 & 2.1 & 1.2 & $59 \%$ & 3.2 & 2.6 & 1.8 \\
\hline $5 \mathrm{w} 0 \mathrm{~g}$ & 10 & $100 \%$ & 1.7 & 1.7 & 1.0 & $93 \%$ & 1.7 & 1.7 & 1.1 & $100 \%$ & 1.7 & 1.7 & 1.0 & $71 \%$ & 1.6 & 1.6 & 1.2 \\
\hline $2 \mathrm{~ns} 0$ & 10 & $95 \%$ & 1.6 & 1.6 & 1.0 & $91 \%$ & 1.4 & 1.4 & 1.0 & $100 \%$ & 1.5 & 1.5 & 1.0 & $60 \%$ & 1.4 & 1.4 & 1.0 \\
\hline $4 \mathrm{dpb}$ & 10 & $98 \%$ & 1.2 & 1.2 & 0.8 & $82 \%$ & 1.2 & 1.2 & 0.8 & $90 \%$ & 1.2 & 1.2 & 0.8 & $51 \%$ & 1.2 & 1.2 & 0.9 \\
\hline 5 nod & 10 & $18 \%$ & 1.2 & 1.2 & 0.7 & $9 \%$ & 3.8 & 2.4 & 1.0 & $25 \%$ & 5.8 & 4.0 & 0.9 & $81 \%$ & 0.9 & 0.9 & 0.9 \\
\hline 6elm & 10 & $21 \%$ & 2.8 & 1.9 & 0.9 & $8 \%$ & 3.5 & 1.2 & 1.0 & $12 \%$ & 3.0 & 1.7 & 0.9 & $25 \%$ & 3.1 & 1.7 & 1.1 \\
\hline 3bv8 & 11 & $100 \%$ & 0.9 & 0.9 & 0.7 & $86 \%$ & 0.8 & 0.8 & 0.7 & $100 \%$ & 0.8 & 0.8 & 0.7 & $84 \%$ & 0.9 & 0.9 & 0.7 \\
\hline $5 e 9 p$ & 12 & $52 \%$ & 5.6 & 2.6 & 1.5 & $16 \%$ & 0.9 & 0.9 & 0.7 & $10 \%$ & 2.0 & 2.0 & 1.2 & $33 \%$ & 6.6 & 4.8 & 2.3 \\
\hline $4 \mathrm{bpf}$ & 13 & $73 \%$ & 0.7 & 0.7 & 0.5 & $96 \%$ & 0.8 & 0.8 & 0.6 & $33 \%$ & 0.8 & 0.8 & 0.6 & $26 \%$ & 3.9 & 3.9 & 3.2 \\
\hline $6 \mathrm{fmb}$ & 13 & $99 \%$ & 1.6 & 1.6 & 0.5 & $8 \%$ & 1.4 & 1.4 & 0.8 & $28 \%$ & 1.6 & 1.6 & 0.6 & $38 \%$ & 1.3 & 1.3 & 0.9 \\
\hline $5 \mathrm{k} 21$ & 13 & $74 \%$ & 1.1 & 1.1 & 0.8 & $2 \%$ & 1.4 & 1.3 & 1.0 & $42 \%$ & 1.3 & 1.3 & 0.8 & $7 \%$ & 13.6 & 12.9 & 11.0 \\
\hline $3 \mathrm{k} 3 \mathrm{v}$ & 14 & $18 \%$ & 4.5 & 2.9 & 1.5 & $3 \%$ & 5.7 & 3.7 & 2.1 & $2 \%$ & 4.0 & 3.4 & 1.7 & $14 \%$ & 2.6 & 2.6 & 1.7 \\
\hline $3 \mathrm{fdr}$ & 14 & $97 \%$ & 1.0 & 1.0 & 0.7 & $8 \%$ & 1.0 & 1.0 & 0.8 & $78 \%$ & 1.0 & 1.0 & 0.8 & $9 \%$ & 4.0 & 4.0 & 3.3 \\
\hline 4qy7 & 14 & $80 \%$ & 2.4 & 0.8 & 0.5 & $4 \%$ & 3.0 & 1.7 & 0.7 & $48 \%$ & 3.0 & 2.2 & 1.4 & $26 \%$ & 3.1 & 2.4 & 1.8 \\
\hline $3 \mathrm{dkm}$ & 16 & $38 \%$ & 4.6 & 4.6 & 2.4 & $3 \%$ & 5.8 & 4.7 & 3.1 & $7 \%$ & 6.4 & 4.1 & 3.7 & $52 \%$ & 4.3 & 4.3 & 3.0 \\
\hline Median & & & 1.6 & 1.6 & 0.8 & & 1.4 & 1.4 & 1.0 & & 1.7 & 1.7 & 0.9 & & 3.1 & 2.4 & 1.7 \\
\hline Mean & & & 2.2 & 1.7 & 1.0 & & 2.3 & 1.8 & 1.1 & & 2.4 & 2.0 & 1.1 & & 3.4 & 3.1 & 2.3 \\
\hline Numbe & $\mathrm{r}<=1.5 \AA$ & & 6 & 7 & 14 & & 8 & 9 & 13 & & 6 & 6 & 13 & & 5 & 5 & 7 \\
\hline Numbe & $r<=3 \AA$ & & 12 & 14 & 15 & & 11 & 13 & 14 & & 12 & 12 & 14 & & 7 & 10 & 12 \\
\hline
\end{tabular}


Table S5. The performance of high-temperature MD simulations compared to REMD simulations with ff19SB+OPC force field

\begin{tabular}{|c|c|c|c|c|c|c|c|c|c|c|c|c|c|c|c|c|c|}
\hline \multicolumn{2}{|c|}{ ff19SB+OPC } & \multicolumn{4}{|c|}{ REMD } & \multicolumn{4}{|c|}{$620 \mathrm{~K}$} & \multicolumn{4}{|c|}{$500 \mathrm{~K}$} & \multicolumn{4}{|c|}{$380 \mathrm{~K}$} \\
\hline $\mathrm{pdb}$ & length & clus1 & top $t$ & top10 & best & clus1 & top & top10 & best & clus1 & top $\mathrm{t}$ & top10 & best & clus1 & top $\mathrm{t}$ & op 10 & best \\
\hline 2eaq & 10 & $54 \%$ & 5.4 & 2.0 & 1.4 & $8 \%$ & 4.7 & 1.9 & 1.1 & $18 \%$ & 2.0 & 2.0 & 0.7 & $37 \%$ & 5.3 & 2.5 & 1.5 \\
\hline $5 \mathrm{w} 0 \mathrm{~g}$ & 10 & $20 \%$ & 3.5 & 1.9 & 0.5 & $7 \%$ & 4.1 & 1.4 & 0.7 & $33 \%$ & 2.8 & 1.4 & 0.5 & $44 \%$ & 0.9 & 0.9 & 0.5 \\
\hline $2 \mathrm{~ns} 0$ & 10 & $85 \%$ & 1.0 & 1.0 & 0.4 & $57 \%$ & 1.2 & 1.2 & 0.5 & $97 \%$ & 0.9 & 0.9 & 0.4 & $27 \%$ & 4.2 & 4.2 & 3.2 \\
\hline $4 \mathrm{dpb}$ & 10 & $100 \%$ & 0.5 & 0.5 & 0.2 & $83 \%$ & 0.6 & 0.6 & 0.4 & $100 \%$ & 0.8 & 0.8 & 0.3 & $28 \%$ & 2.7 & 2.6 & 2.1 \\
\hline 5 nod & 10 & $65 \%$ & 2.4 & 1.7 & 0.5 & $9 \%$ & 2.7 & 2.2 & 0.8 & $25 \%$ & 2.6 & 0.8 & 0.6 & $81 \%$ & 2.7 & 0.9 & 0.5 \\
\hline 6elm & 10 & $28 \%$ & 1.6 & 1.6 & 0.6 & $28 \%$ & 5.0 & 1.4 & 1.0 & $9 \%$ & 1.6 & 1.6 & 0.9 & $32 \%$ & 1.6 & 1.6 & 0.6 \\
\hline 3bv8 & 11 & $100 \%$ & 0.5 & 0.5 & 0.2 & $92 \%$ & 0.5 & 0.5 & 0.3 & $99 \%$ & 0.6 & 0.6 & 0.3 & $33 \%$ & 3.4 & 2.2 & 1.6 \\
\hline $5 e 9 p$ & 12 & $19 \%$ & 5.1 & 2.0 & 0.3 & $13 \%$ & 2.2 & 1.2 & 0.6 & $18 \%$ & 2.2 & 0.4 & 0.3 & $68 \%$ & 3.1 & 3.1 & 2.0 \\
\hline $4 \mathrm{bpf}$ & 13 & $78 \%$ & 0.4 & 0.4 & 0.3 & $99 \%$ & 0.6 & 0.6 & 0.3 & $67 \%$ & 0.5 & 0.5 & 0.3 & $31 \%$ & 4.3 & 4.3 & 3.4 \\
\hline $6 \mathrm{fmb}$ & 13 & $58 \%$ & 1.9 & 1.5 & 0.6 & $13 \%$ & 1.8 & 1.3 & 0.8 & $7 \%$ & 4.3 & 4.3 & 1.9 & $33 \%$ & 10.4 & 6.5 & 5.4 \\
\hline $5 \mathrm{k} 2 \mathrm{l}$ & 13 & $94 \%$ & 0.6 & 0.6 & 0.3 & $7 \%$ & 1.8 & 0.8 & 0.6 & $51 \%$ & 1.9 & 0.5 & 0.4 & $18 \%$ & 2.5 & 2.5 & 2.1 \\
\hline $3 \mathrm{k} 3 \mathrm{v}$ & 14 & $28 \%$ & 7.2 & 4.4 & 1.1 & $1 \%$ & 4.8 & 2.4 & 1.5 & $2 \%$ & 13.6 & 3.0 & 1.7 & $9 \%$ & 4.4 & 3.9 & 3.3 \\
\hline $3 \mathrm{fdr}$ & 14 & $13 \%$ & 5.9 & 5.9 & 0.8 & $2 \%$ & 7.6 & 4.3 & 1.9 & $11 \%$ & 6.0 & 5.3 & 2.8 & $14 \%$ & 6.8 & 4.8 & 3.5 \\
\hline 4qy7 & 14 & $68 \%$ & 2.6 & 1.0 & 0.6 & $18 \%$ & 1.2 & 1.2 & 0.6 & $61 \%$ & 2.4 & 0.9 & 0.6 & $33 \%$ & 2.6 & 2.6 & 2.2 \\
\hline $3 \mathrm{dkm}$ & 16 & $54 \%$ & 8.1 & 6.2 & 3.1 & $3 \%$ & 9.3 & 7.3 & 3.9 & $8 \%$ & 9.1 & 6.0 & 4.0 & $33 \%$ & 16.2 & 7.8 & 6.6 \\
\hline Median & & & 2.4 & 1.6 & 0.5 & & 2.2 & 1.3 & 0.7 & & 2.2 & 0.9 & 0.6 & & 3.4 & 2.6 & 2.1 \\
\hline Mean & & & 3.1 & 2.1 & 0.7 & & 3.2 & 1.9 & 1.0 & & 3.4 & 1.9 & 1.1 & & 4.7 & 3.4 & 2.6 \\
\hline Numbe & $\mathrm{r}<=1.5 \AA$ & & 5 & 7 & 14 & & 5 & 10 & 13 & & 4 & 9 & 11 & & 1 & 2 & 4 \\
\hline Numbe & $\mathrm{r}<=3 \AA$ & & 9 & 12 & 14 & & 9 & 13 & 14 & & 11 & 12 & 14 & & 6 & 8 & 9 \\
\hline
\end{tabular}




\section{Supplementary Figures 1-15}
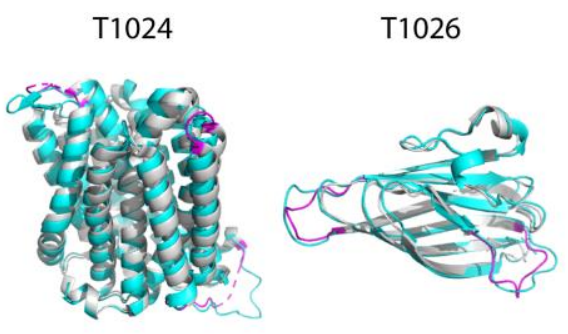

T1031

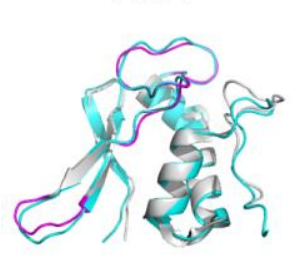

T1038

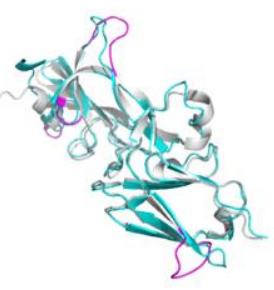

T1043

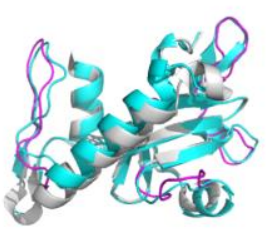

T1064

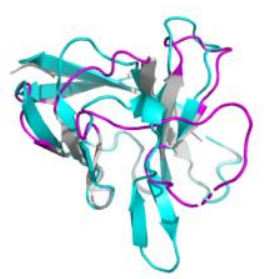

$\mathrm{T} 1032$

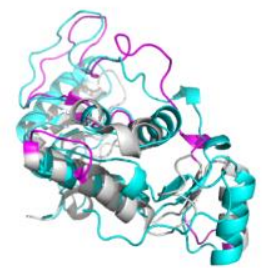

T1039

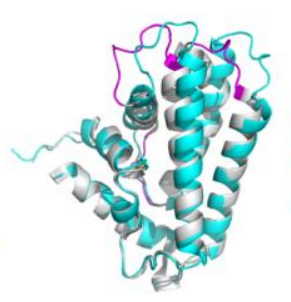

T1046s1

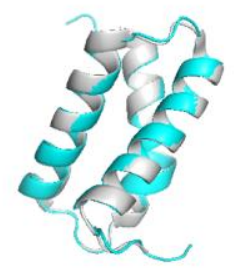

T1082

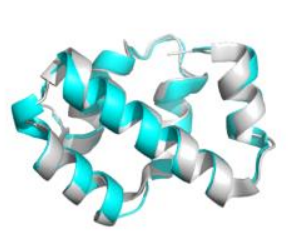

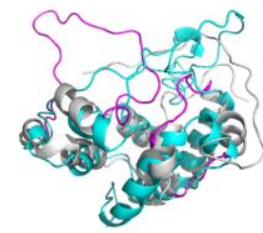

T1027

T1033

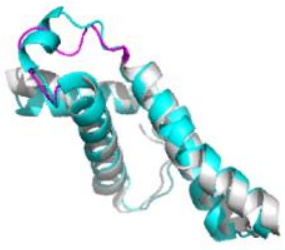

T1040

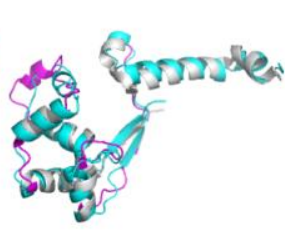

$\mathrm{T} 1046 \mathrm{~s} 2$

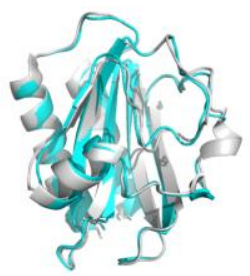

T1090

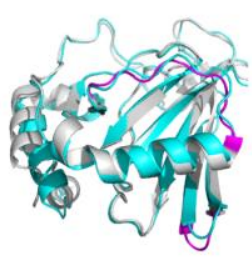

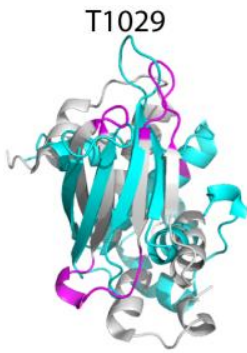

$\mathrm{T} 1030$

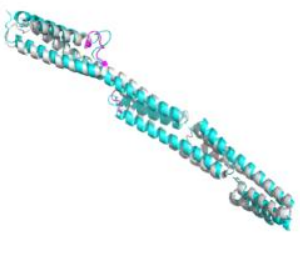

T1037
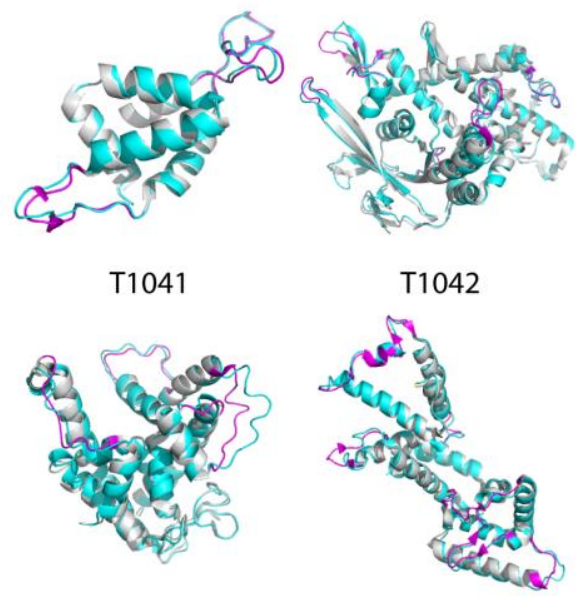

T1056
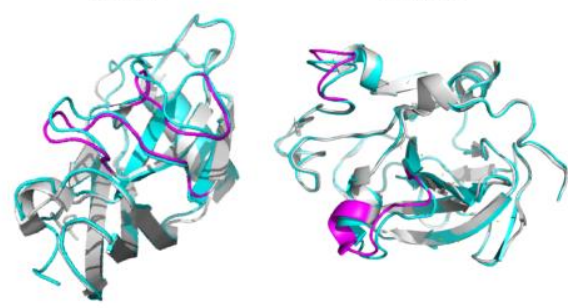

T1099

Figure S1. The best models (in cyan) from AlphaFold2 (group \#427 in CASP14) are aligned to experimental structures (in gray), where some poorly predicted loop regions are shown in magenta. 


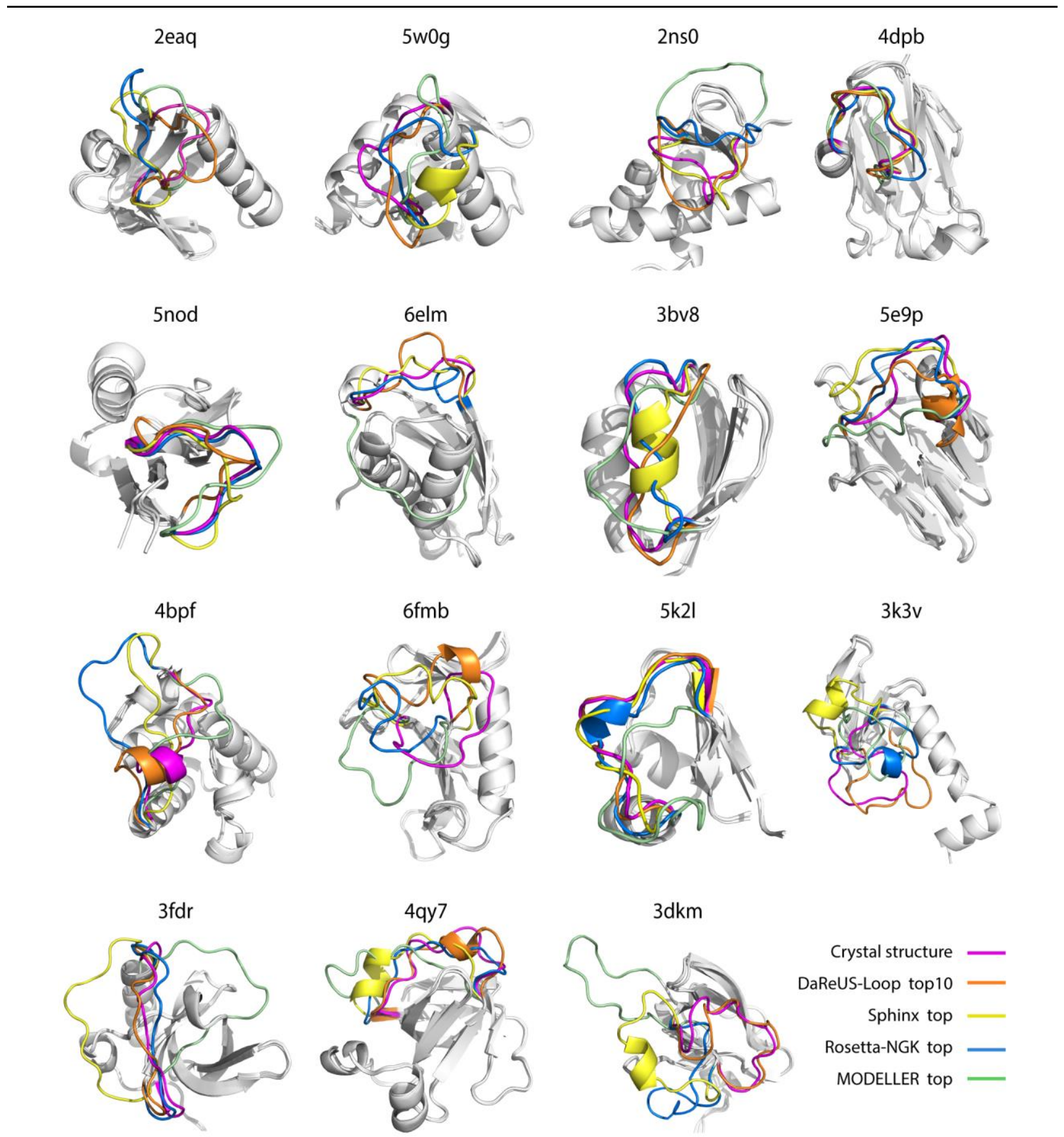

Figure S2. Predicted structures (i.e. the "top" structures of Sphinx, Rosetta-NGK, MODELLER and the "top10" structures of DaReUS-Loop) are presented as cartoons aligned to the crystal structures. Loop regions are in magenta (crystal structure), orange (DaReUS-Loop), yellow (Sphinx), blue (Rosetta-NGK), green (MODELLER), respectively. 


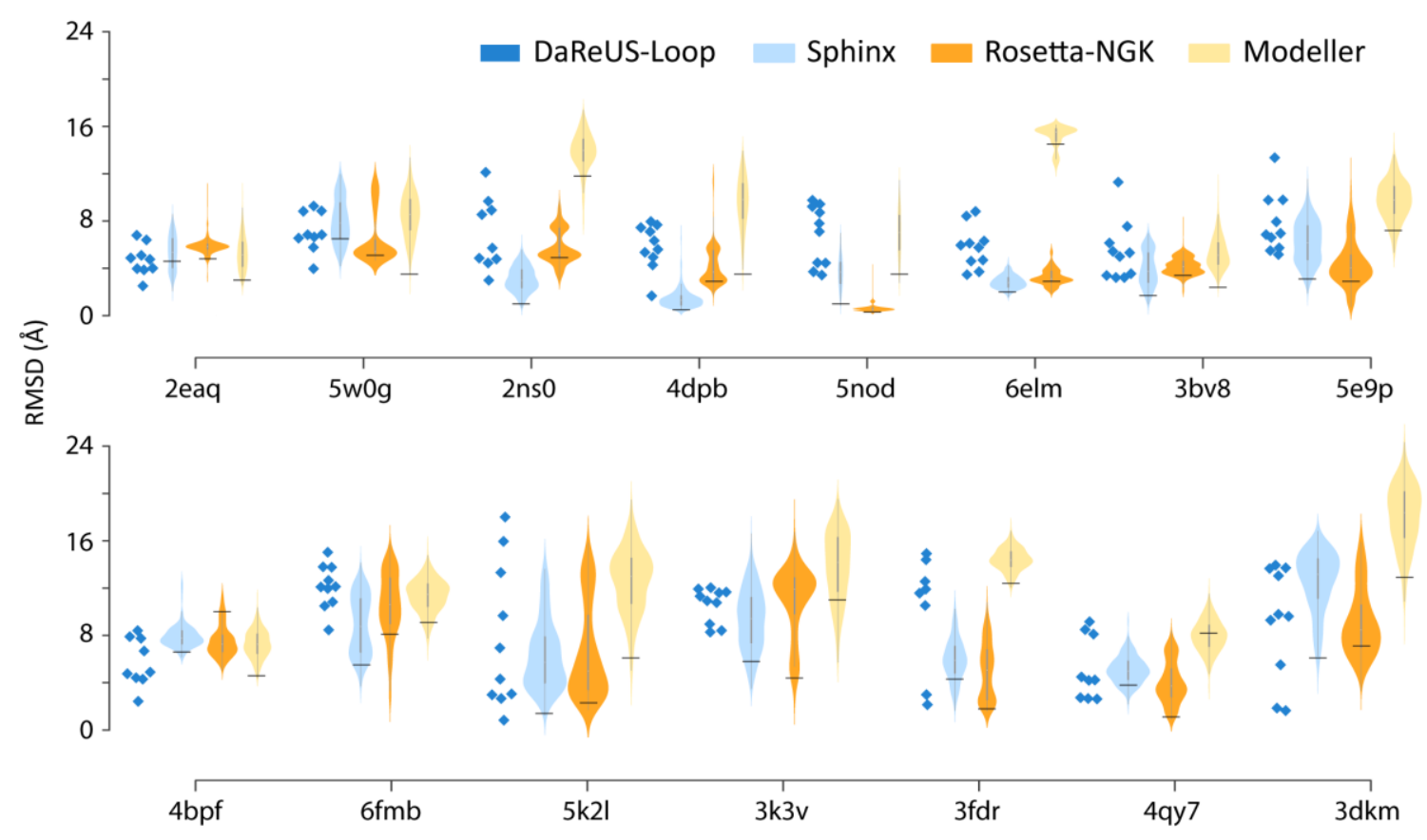

Figure S3. Distribution of C $\alpha$ RMSD of models generated by each method. Different colors distinguish different methods (DaReUS-Loop: dark blue; Sphinx: light blue, Rosetta-NGK: orange; MODELLER: yellow). The solid black lines indicate the RMSD of the "top" model. 


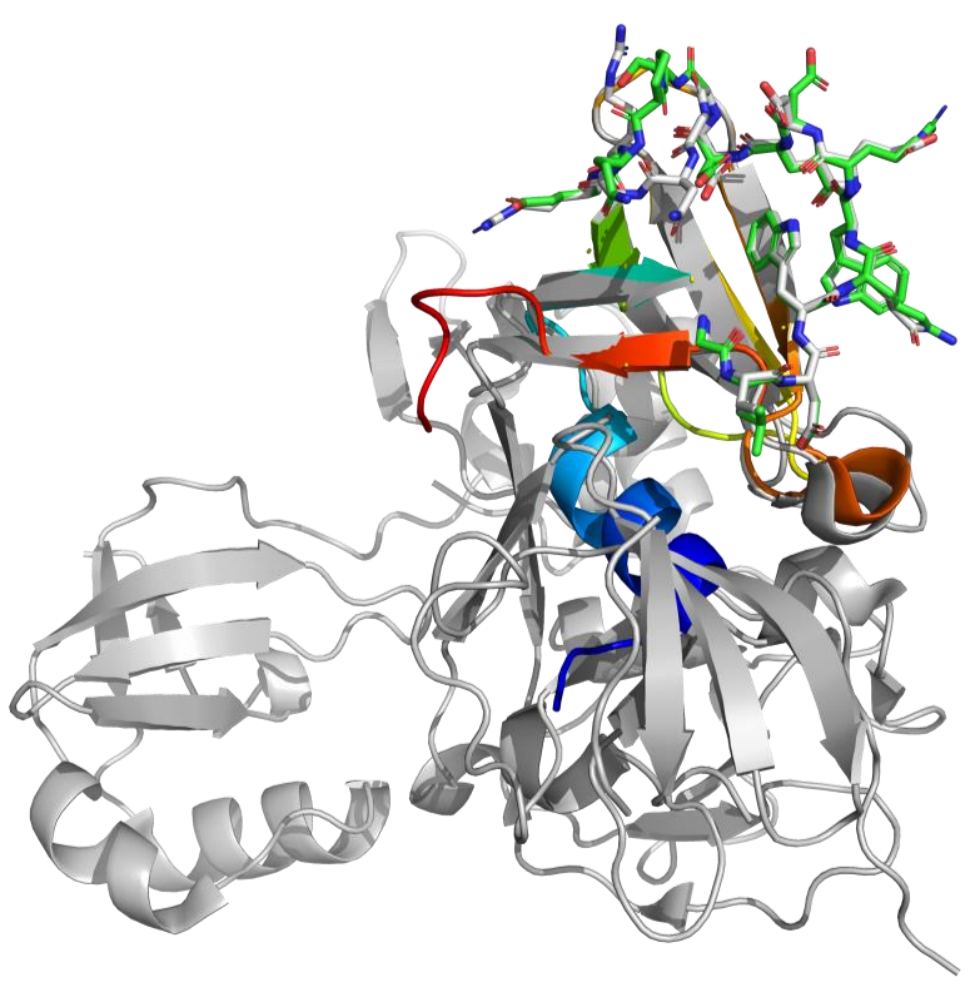

Figure S4. Crystal structure of 3dkm (in rainbow) is aligned to the top10 models' template (in grey, pdbID 4xi7) from DaReUS-Loop. Loop residues are shown as sticks and all hydrogens are hidden. 

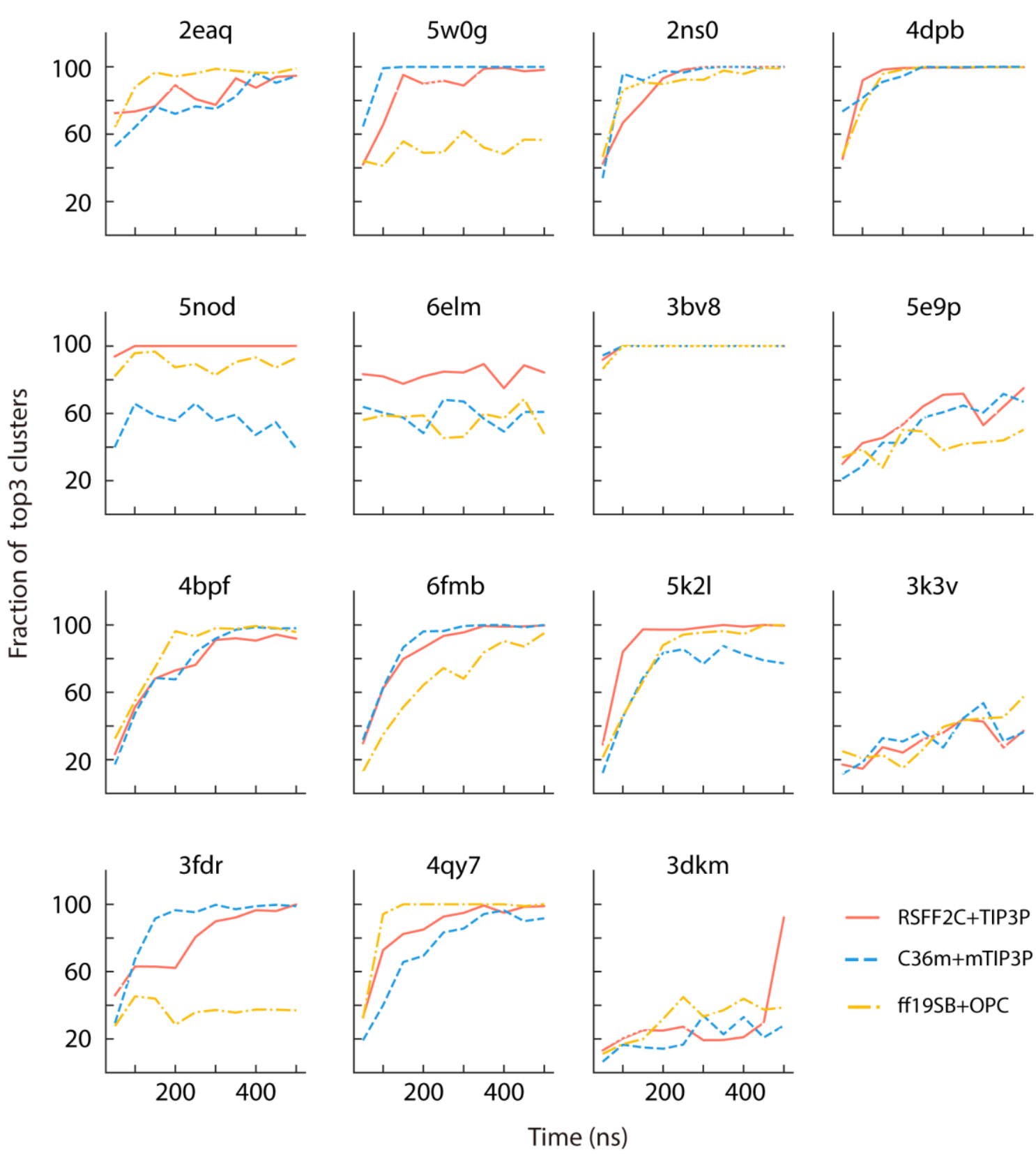

Figure S5. The time evolution of the fraction of top3 conformation clusters. The "top3" denotes the first 3 cluster centroids from REMD simulations per $50 \mathrm{~ns}$ and the cutoff for all proteins was set to $0.8 \AA$. 


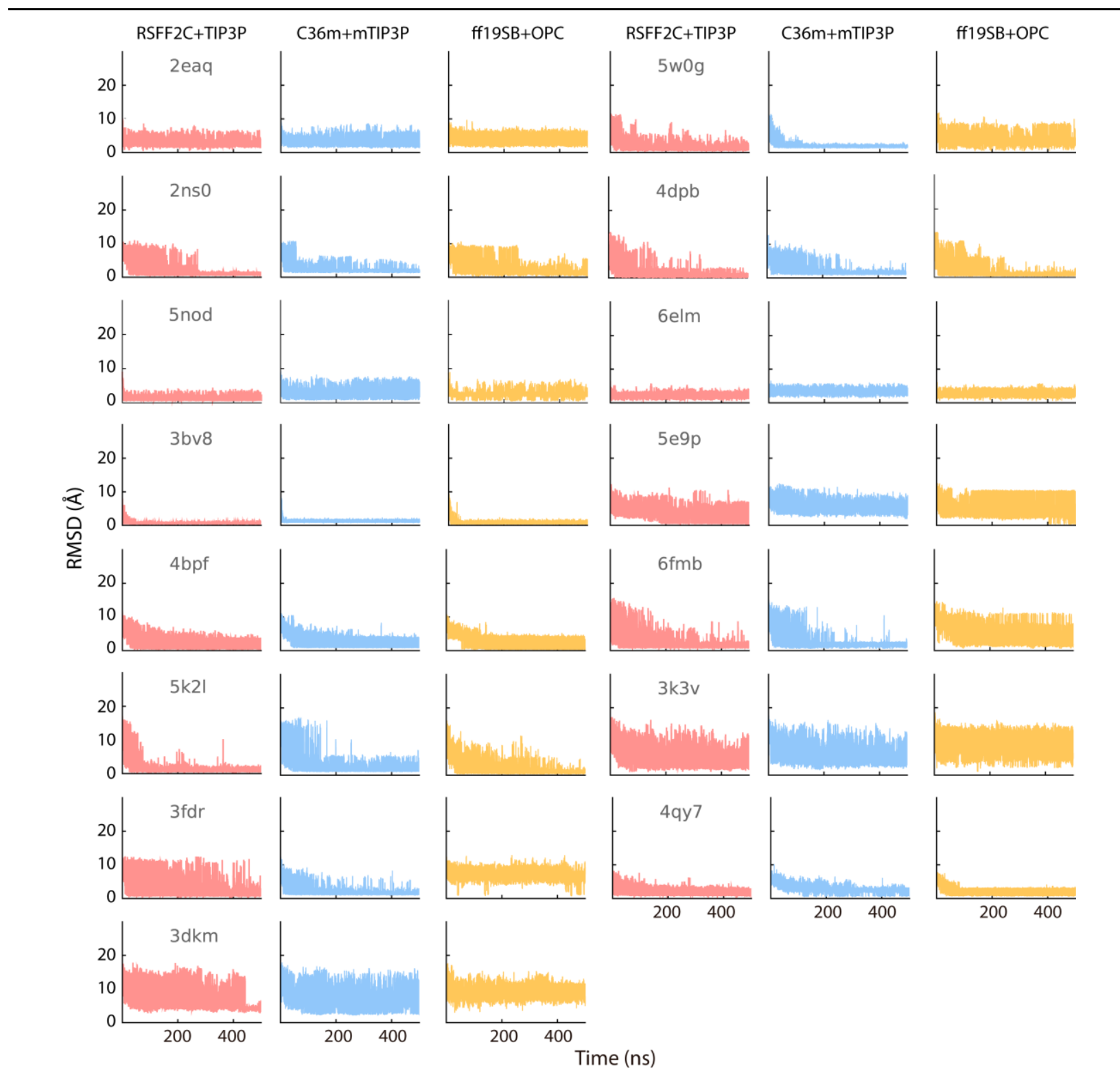

Figure S6. Temporal evolution of the loops' C $\alpha$ RMSD to crystal structures in the lowest replica of 500-ns REMD simulations. 


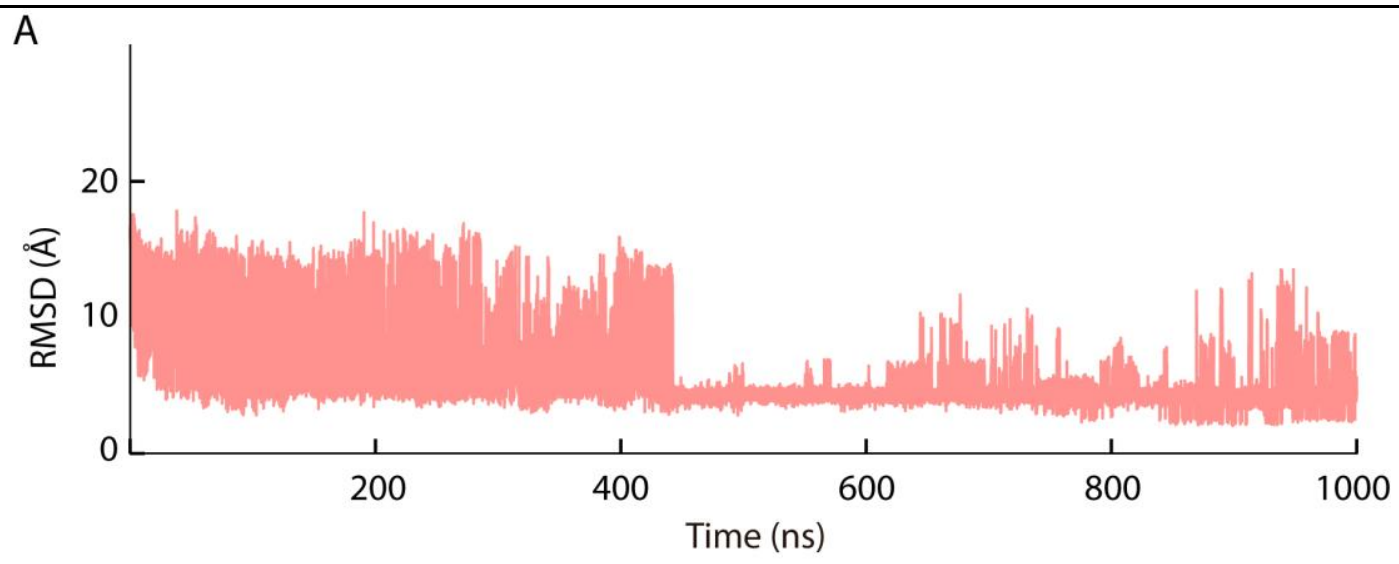

B

\begin{tabular}{ccccc}
\hline & $300-500 \mathrm{~ns}$ & $500-1000 \mathrm{~ns}$ & $500-800 \mathrm{~ns}$ & $800-1000 \mathrm{~ns}$ \\
\hline $\mathrm{C} 1$ & $4.1(56 \%)$ & $4.1(94 \%)$ & $4.3(93 \%)$ & $4.2(92 \%)$ \\
$\mathrm{C} 2$ & $7.1(7 \%)$ & $6.2(3 \%)$ & $6.1(4 \%)$ & $8.2(3 \%)$ \\
$\mathrm{C} 3$ & $8.0(5 \%)$ & $8.1(1 \%)$ & $4.2(2 \%)$ & $6.7(2 \%)$ \\
\hline
\end{tabular}

C

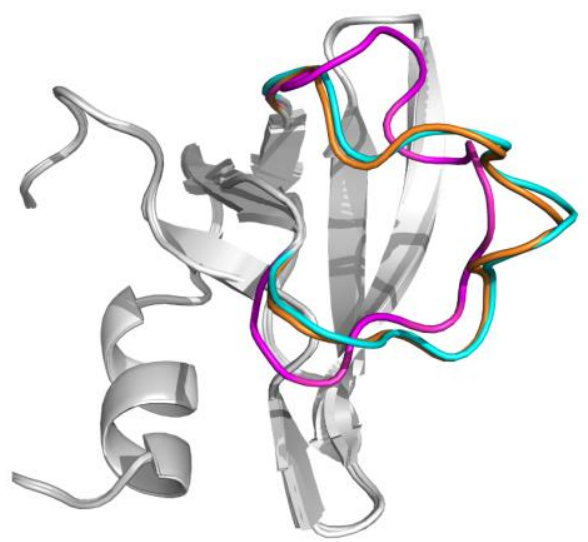

Crystal structure

$300-500$ ns top

$500-1000$ ns top

Figure S7. (A) Temporal evolution of the Ca RMSD in 1000 ns REMD simulations with RSFF2C+TIP3P. (B) Comparison of the first three cluster centroids from clustering analysis of 300-500 ns and 500-1000 ns trajectories. The RMSD for each cluster is given in $\AA$ and the fraction (in parenthesis) is given in percentage. (C) Comparison of the predicted structures from 300-500 ns (cyan) and 500-1000 ns (orange) REMD simulations with RSFF2C+TIP3P. Structures are shown as cartoons aligned to the crystal structure (magenta). 


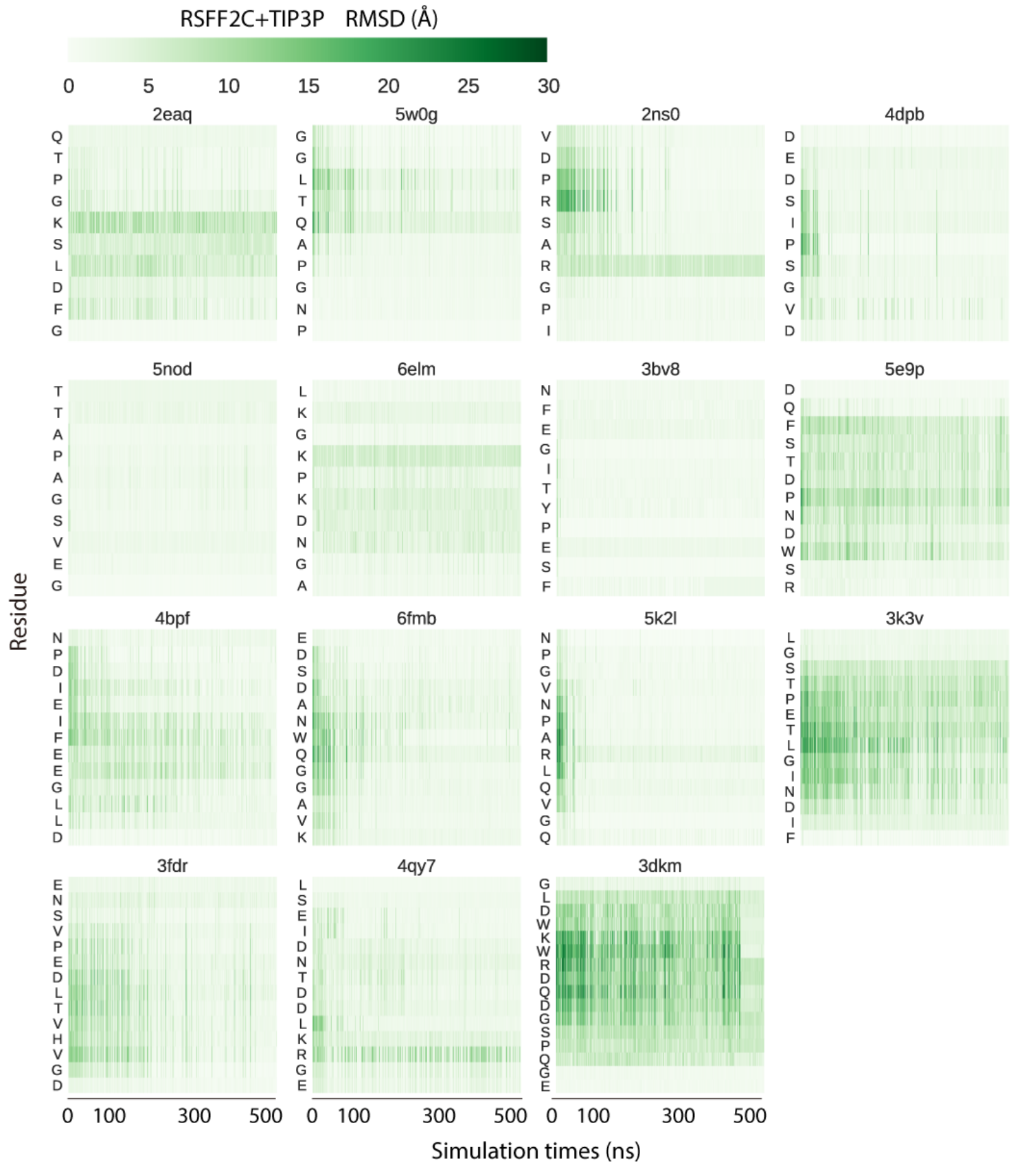

Figure S8. Temporal evolution of the C $\alpha$ RMSD per residue compared to crystal structures in 500 ns REMD simulations of RSFF2C+TIP3P. Darker green indicates higher RMSD values. 


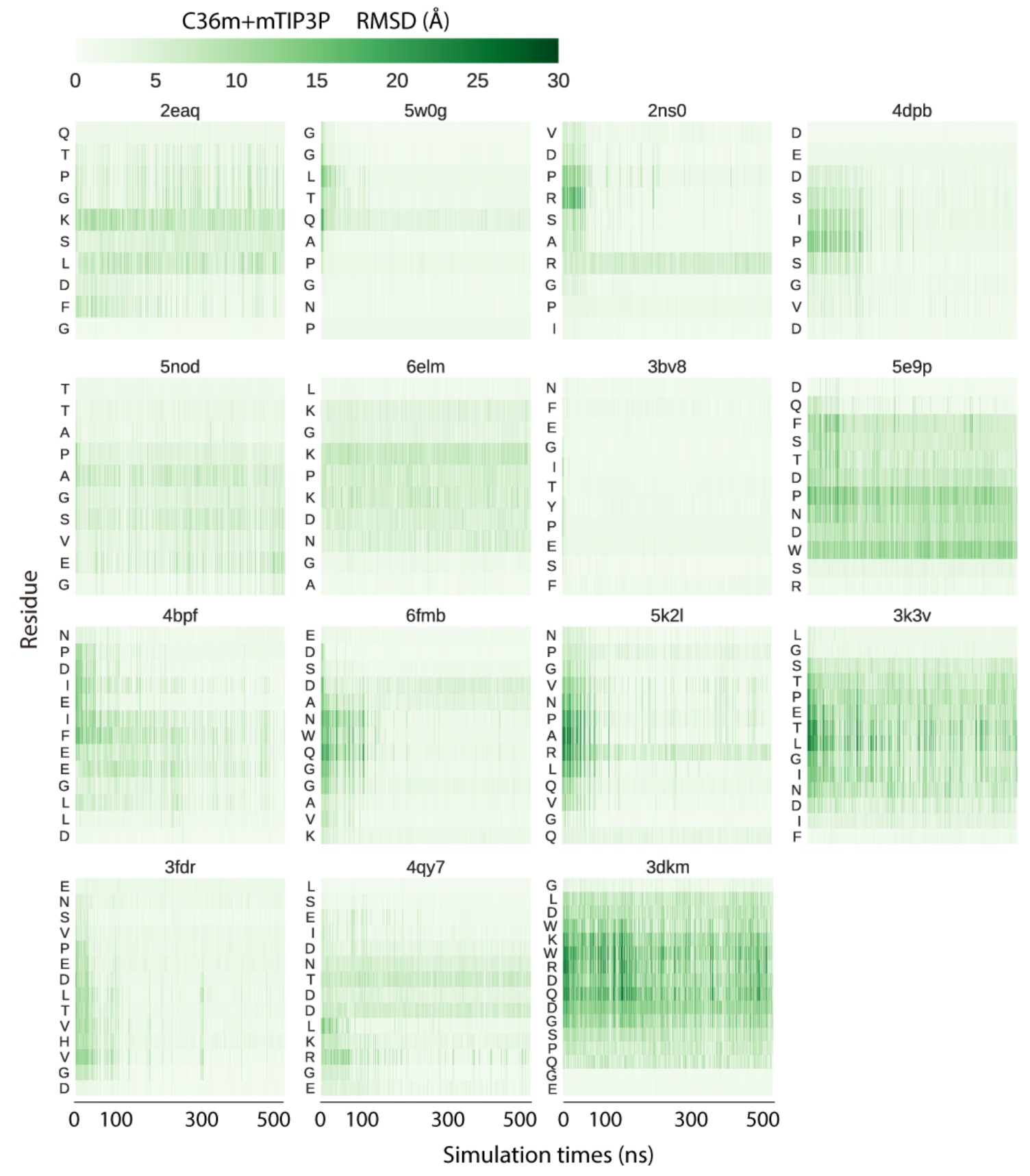

Figure S9. Temporal evolution of the C $\alpha$ RMSD per residue compared to crystal structures in 500 ns REMD simulations with C36m+mTIP3P. Darker green indicates higher RMSD values. 


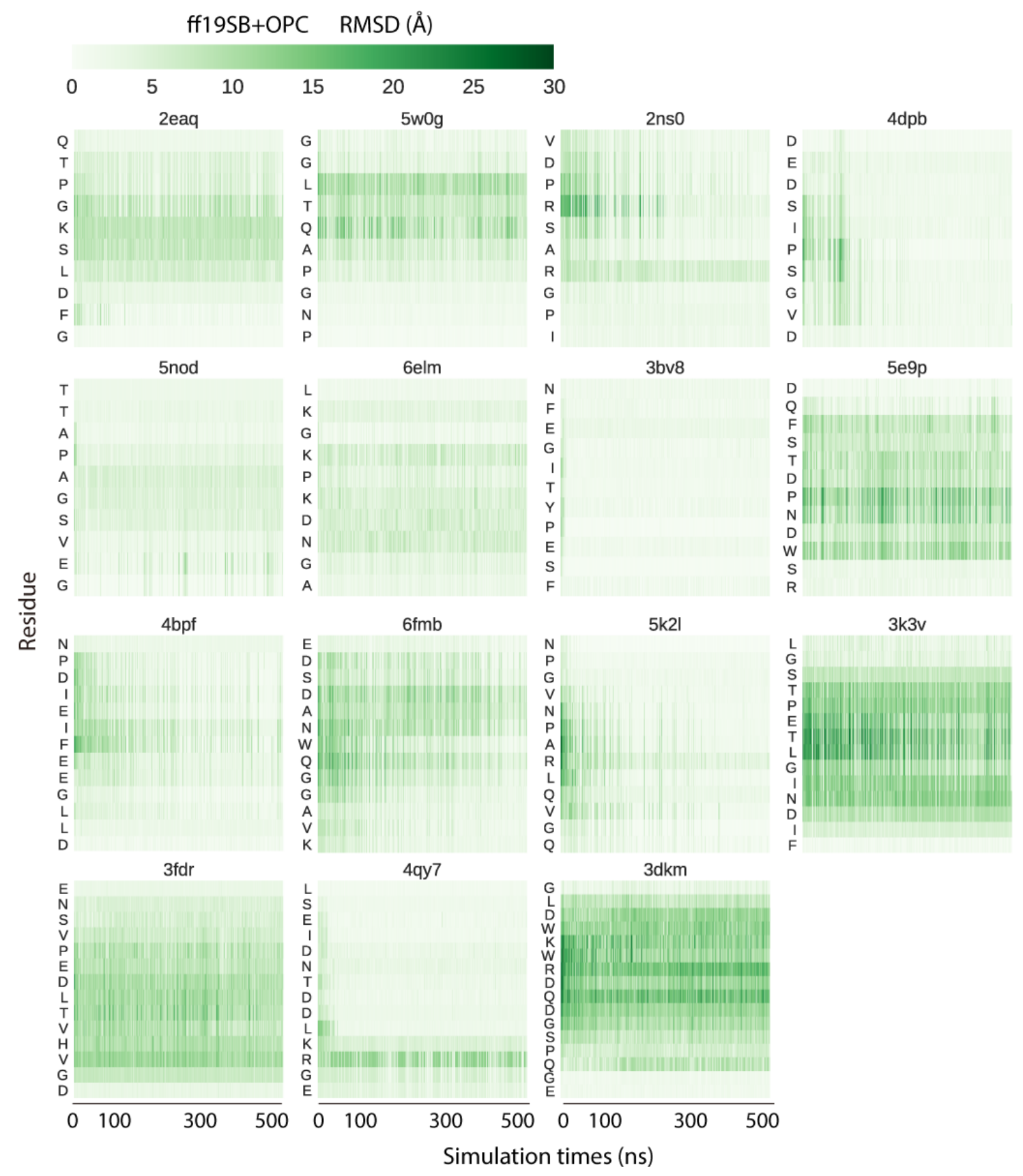

Figure S10. Temporal evolution of C $\alpha$ RMSD per residue compared to crystal structures in 500 ns REMD simulations of ff19SB+OPC. Darker green indicates higher RMSD values. 


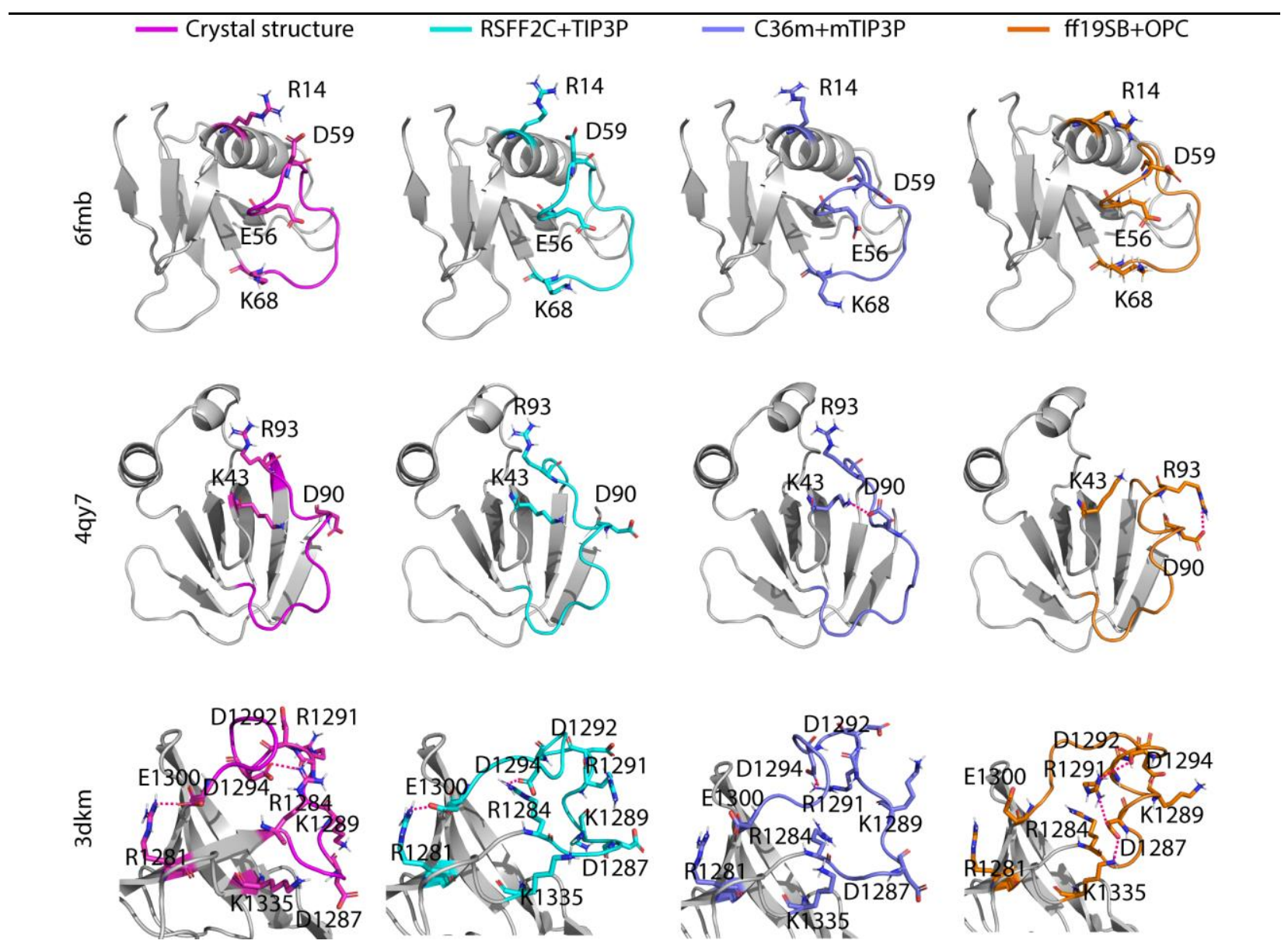

Figure S11. The loop regions of the largest cluster (i.e. the "top" structures) and the crystal structures of $6 \mathrm{fmb}, 4 \mathrm{qy} 7$ and $3 \mathrm{dkm}$ from REMD simulations are presented as cartoons. Loop regions are in magenta (crystal structure), cyan (RSFF2C+TIP3P), purple (C36m+mTIP3P), orange (ff19SB+OPC), respectively. The residues in stable salt bridges (listed in Table3) are shown as sticks and nonpolar hydrogens are hidden. Salt bridges are represented by pink dashed lines. 


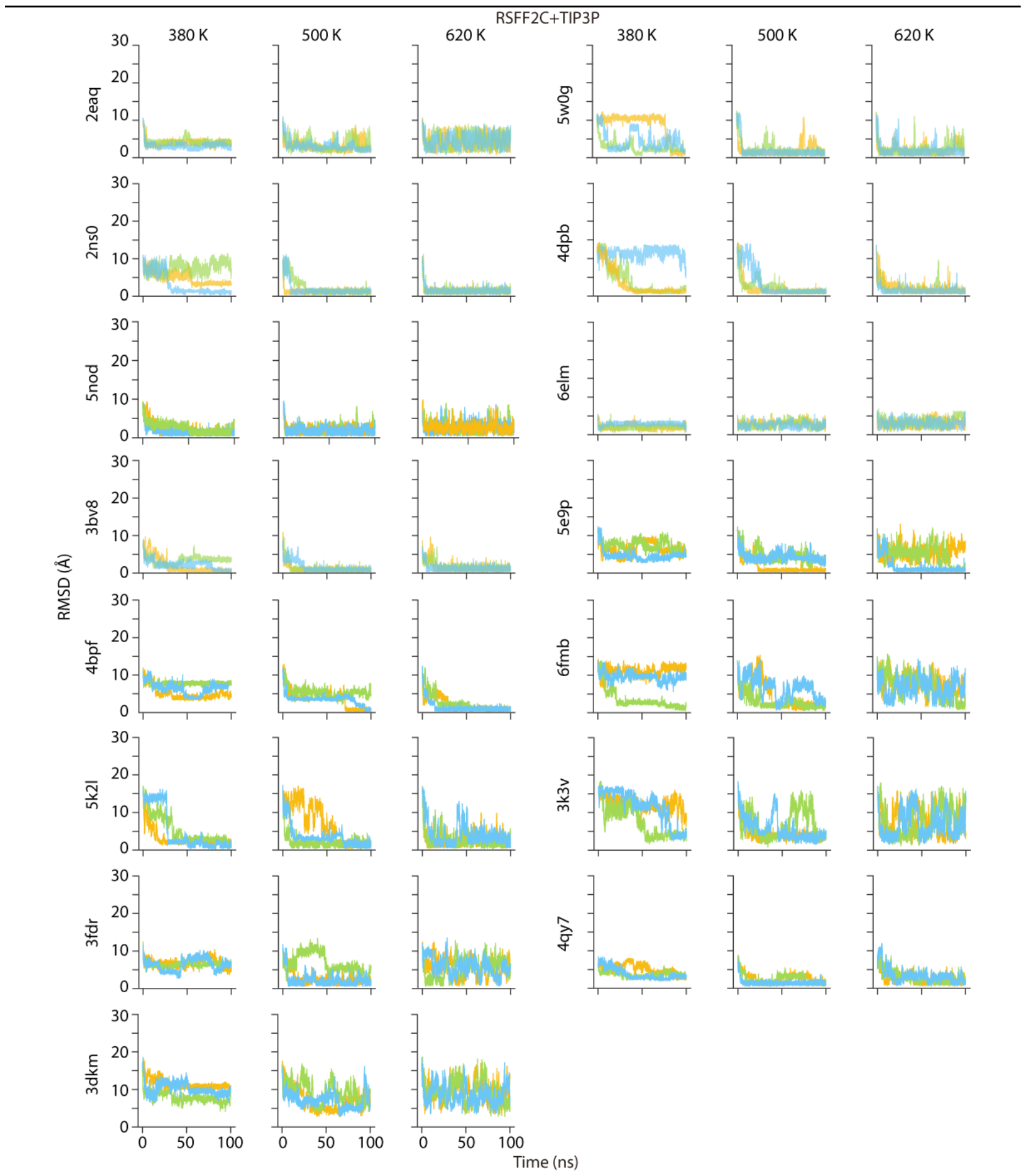

Figure S12. Temporal evolution of C $\alpha$ RMSD compared to crystal structures in 100 ns MD simulations with RSFF2C+TIP3P. For each loop, there were three temperatures $(380 \mathrm{~K}, 500 \mathrm{~K}$, $620 \mathrm{~K})$. At each temperature, three independent simulations were performed. 

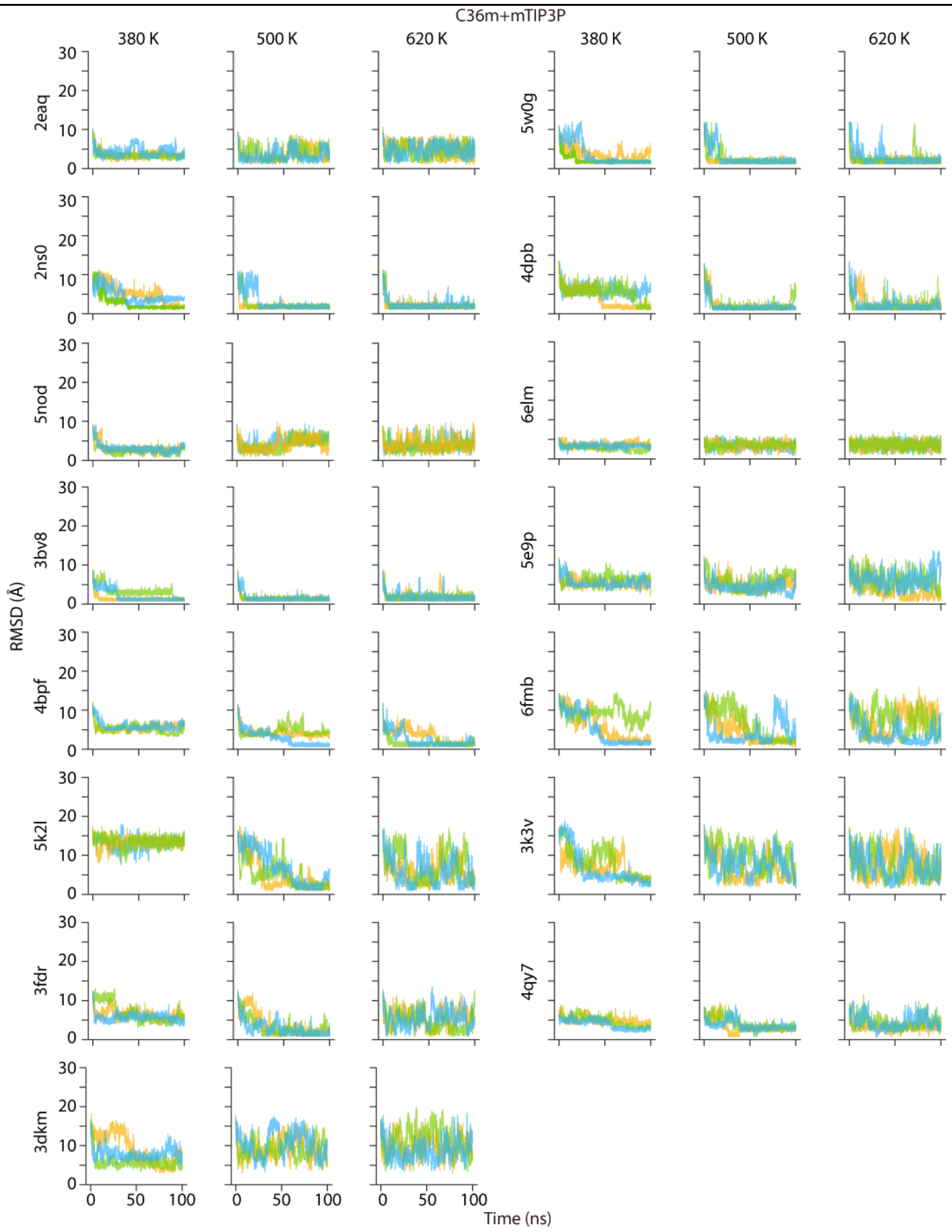

Figure S13. Temporal evolution of C $\alpha$ RMSD compared to crystal structures in 100 ns MD simulations with C36m+mTIP3P. For each loop, there were three temperatures $(380 \mathrm{~K}, 500 \mathrm{~K}$, $620 \mathrm{~K})$. At each temperature, three independent simulations were performed. 

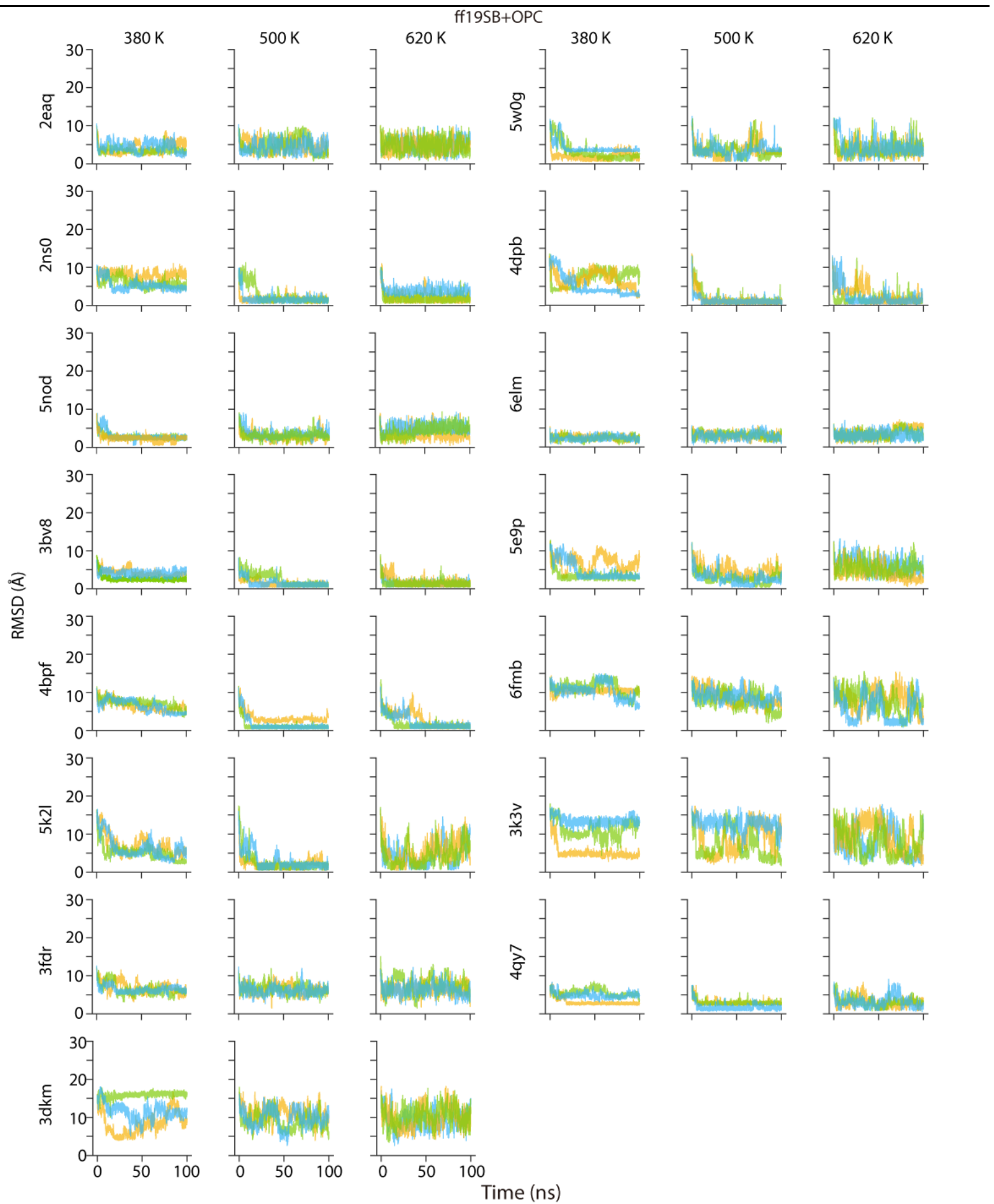

Figure S14. Temporal evolution of C $\alpha$ RMSD compared to crystal structures in 100 ns MD simulations with ff19SB+OPC. For each loop, there were three temperatures $(380 \mathrm{~K}, 500 \mathrm{~K}, 620$ $\mathrm{K})$. At each temperature, three independent simulations were performed. 


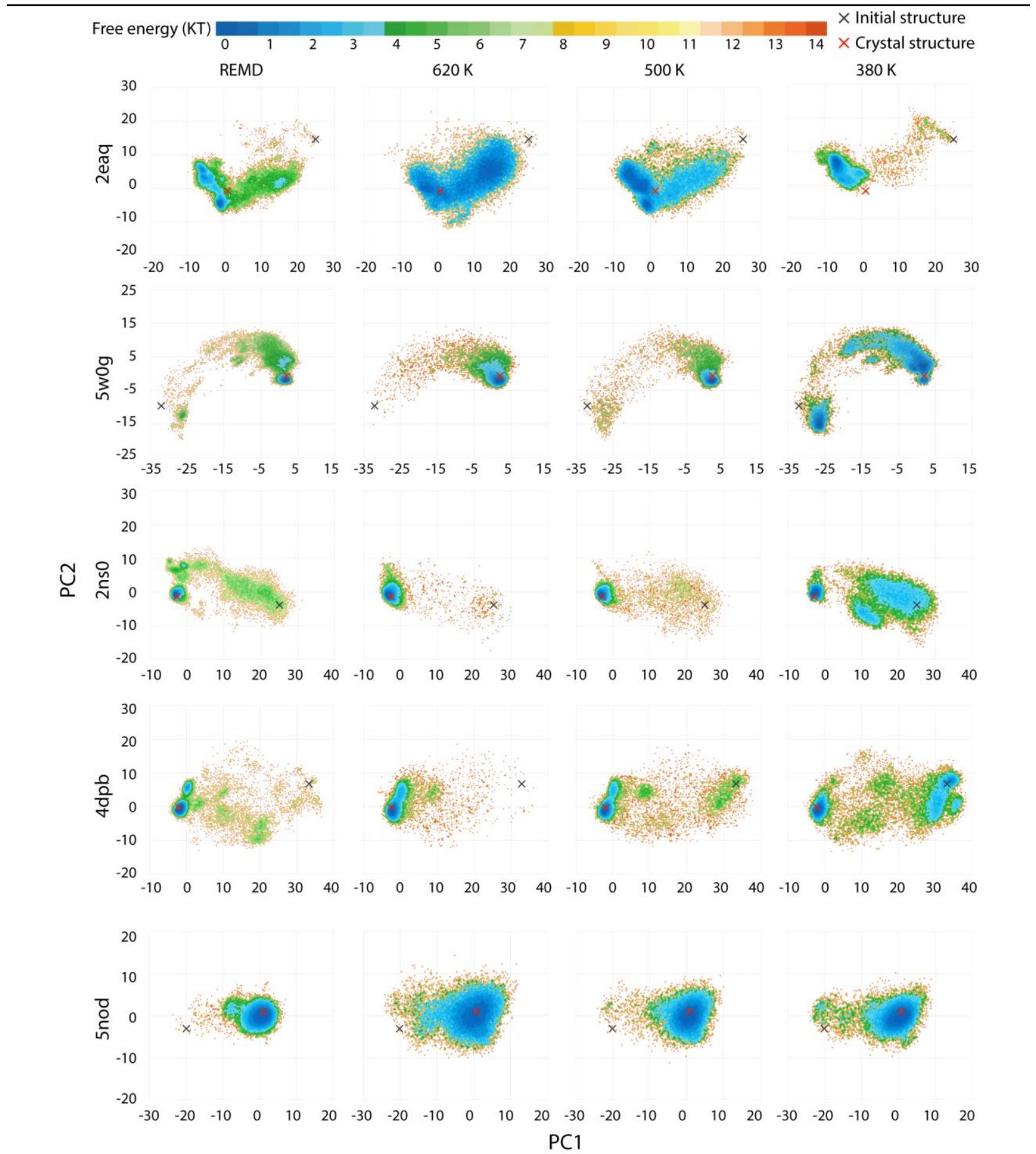

Figure S15.a Free energy landscapes of REMD simulations and high-temperature ( $380 \mathrm{~K}, 500 \mathrm{~K}$, $620 \mathrm{~K}$ ) simulations of loops (2eaq, $5 \mathrm{w} 0 \mathrm{~g}$, 2ns0, 4dpb and 5nod) with RSFF2C+TIP3P along the first two principal components. 

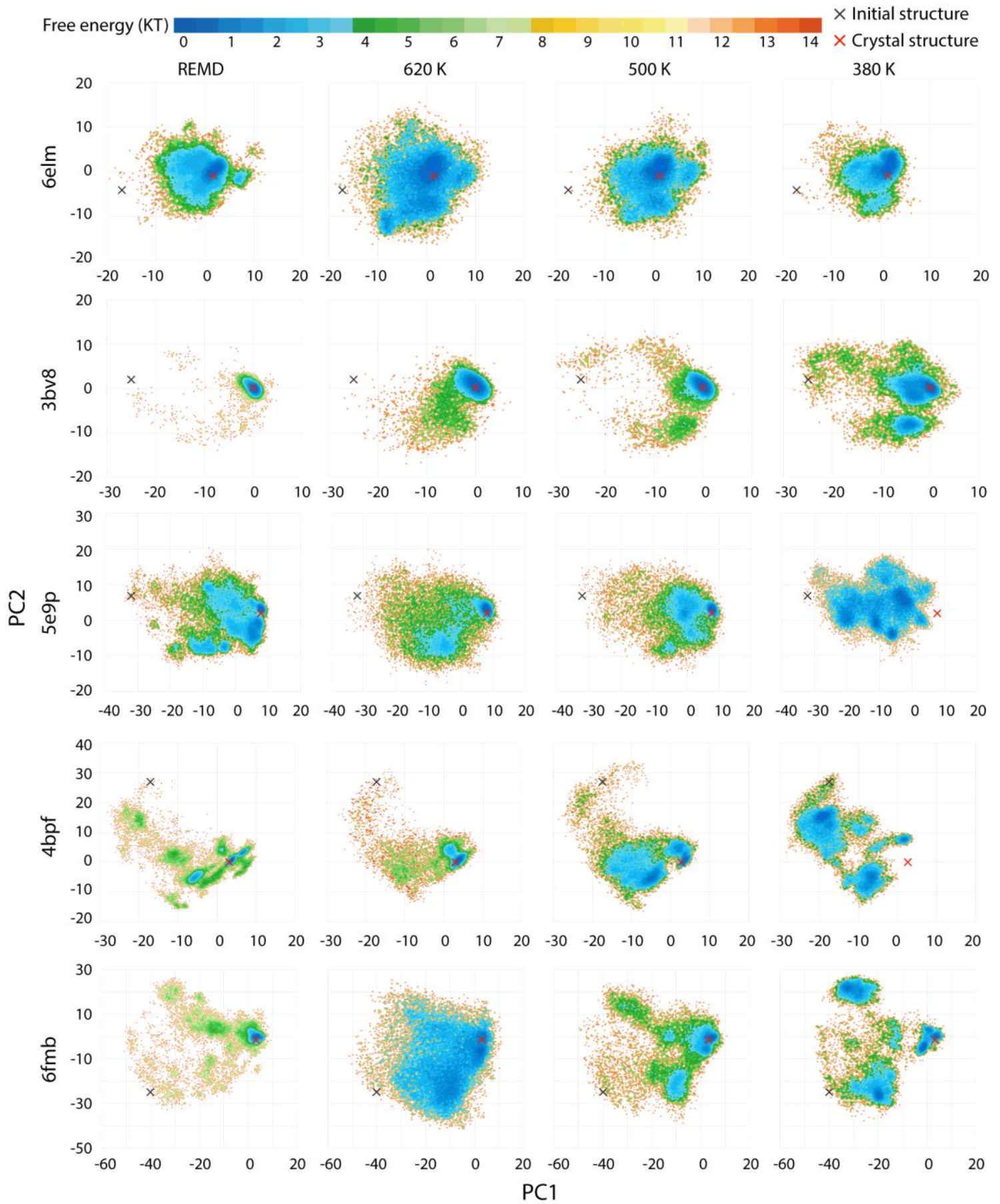

Figure S15.b Free energy landscapes of REMD simulations and high-temperature $(380 \mathrm{~K}, 500 \mathrm{~K}$, $620 \mathrm{~K}$ ) simulations of loops (6elm, 3bv8, 5e9p, 4bpf and 6fmb) with RSFF2C+TIP3P along the first two principal components. 


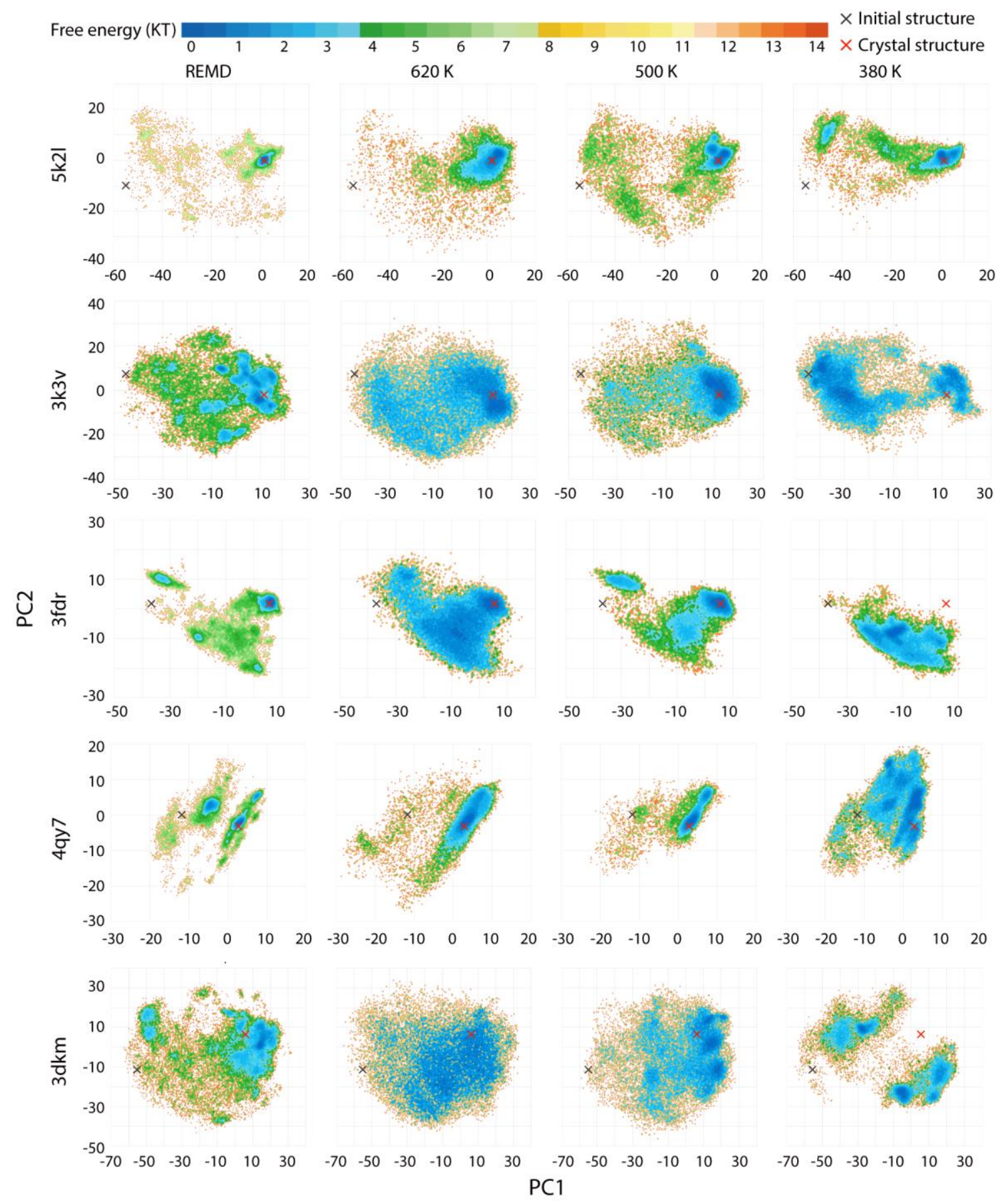

Figure S15.c Free energy landscapes of REMD simulations and high-temperature $(380 \mathrm{~K}, 500 \mathrm{~K}$, $620 \mathrm{~K})$ simulations of loops (5k2l, 3k3v, 3fdr, 4qy7 and 3dkm) with RSFF2C+TIP3P along the first two principal components. 


\section{Rosetta-NGK and MODELLER prediction details Rosetta-NGK}

rosetta_bin_linux_2019.35.60890_bundle/main/source/bin/loopmodel.static.linuxgccrelease -ex1 -ex2 -extrachi_cutoff 0 -in:file:fullatom -loops::remodel perturb_kic -loops::refine refine_kic -kic_bump_overlap_factor 0.36 -legacy_kic false -loops:kic_min_after_repack true -loops:kic_omega_sampling -loops:allow_omega_move true -loops:ramp_fa_rep -loops:ramp_rama -loops:kic_rama2b -loops:loop_file XXXX.loop -s XXXX.Init.pdb -nstruct 500

\section{MODELLER}

$\mathrm{a}=$ automodel(env, alnfile=pdbID +'.temp.ali', knowns= 'pdb file with missing loop', sequence='complete sequence', assess_methods=(assess.DOPE)

a.starting_model $=1$

a.ending_model $=500$

a.make()

Using 2eaq as an example

"2eaq.temp.ali" File contents

$>$ P1;template

structureX:XXXX.del.pdb: $\quad 1::+79 \quad::::-1.00:-1.00$

QFSDMRISIN---------FTIKWDIPGIFVASVEAGSPAEFSQLQVDDEIIAINNTKFSYNDSKE WEEAMAKAQETGHLVMDVRRYG*

$>\mathrm{P} 1 ;$ target

sequence:XXXX: $\quad:: \quad:::: 0.00: 0.00$

QFSDMRISINQTPGKSLDFGFTIKWDIPGIFVASVEAGSPAEFSQLQVDDEIIAINNTKFSYN DSKEWEEAMAKAQETGHLVMDVRRYG* 


\section{DaReUS-Loop and Sphinx prediction details}

For benchmarking purposes, the protein itself and its homologs (100\% sequence identity) should be removed from the template database. Here, we searched the PDB and found these entries should be excluded.

3fdr: 6pi7, 6b57, 5j39, 2diq

$3 \mathrm{k} 3 \mathrm{v}: 3 \mathrm{fma}$

4dpb: 4dpc 4dpa 1tkw 4dp7 3pcy 4pcy 6pcy 5pcy 1pnc 2pcy 1pnd 1plc 4dp9 4dp8

4qy7: 2jqo

5e9p: $6 \mathrm{ffu} 6 \mathrm{ffq}$

5k21: $5 \mathrm{yzk}$

5w0g: 4tu9, 4tu8, 4ty7, 3vam, 3val, 3vak, 3vaj, 3vai, 3vah, 3vag, 3vaf, 2hzc, 2g4b, 5ev4, 2yh0,5ev2, 5ev3, 5ev1, 1u2f, 2yh1, 6tr0

6elm: 6fbk

For DaReUS-Loop, we used "remodeling" for loop predictions. It is said that the user can define a PDB code that will be removed from the search, including its close homologs (> $70 \%$ sequence identity). However, we found that this function did not work as intended and it did not remove the homologs with $100 \%$ sequence identity. So, to ensure a fair comparison, before analysis we manually excluded the models that used the homologs with $100 \%$ sequence identity as templates. For Sphinx, we selected the general version for loop predictions and above listed entries were included in the so-called PDB blacklist. 